\title{
METASTASIS EN INJERTO RENAL DE ADENOCARCINOMA RENAL PRIMARIO
}

\author{
I. GÓMEZ GARCÍA, F.J. BURGOS REVILLA, E. SANZ MAYAYO, S. CONDE SOMESO, \\ C. QUICIOS DORADO, J. PASCUAL, R. MARCÉN, A. ESCUDERO BARRILERO
}

Servicio de Urología. Servicio de Nefrología. Hospital Ramón y Cajal. Madrid.

Actas Urol Esp. 28 (6): 458-461, 2004

\section{RESUMEN}

METÁSTASIS EN INJERTO RENAL DE ADENOCARCINOMA RENAL PRIMARIO

La enfermedad renal quística adquirida (E.R.Q.A), es un factor de riesgo para el desarrollo de carcinoma renal en los riñones propios, tras el trasplante renal (T.R.). El desarrollo de un tumor primitivo del injerto renal es infrecuente. De otro lado, la incidencia de tumor primitivo en el injerto renal es infrecuente, pero la presencia de metástasis en el de un tumor epitelial es excepcional, siendo este el segundo caso de literatura de metástasis de tumor epitelial en injerto renal; y el primer caso descrito de metástasis de carcinoma de células renales (C.C.R.), sobre injerto renal. El caso de un paciente con TR normofuncionante y ERQA que desarrolla CCR en riñón propio, con metástasis sobre el injerto renal.

PALABRAS CLAVE: Enfermedad renal quistica adquirida. Trasplante renal. Adenocarcinoma renal.

\section{ABSTRACT \\ METASTASIS IN RENAL GRAFT OF PRIMARY RENAL ADENOCARCINOMA}

Acquired cystic renal disease (A.C.R.D.) is a risk factor for the development of renal carcinoma in the patient's own kidney after renal transplant (R.T.). development of a primitive tumor in the renal graft is infrequent, but the presence of metastasis of an epithelial tumor is very rare. This is the second case reported in the literature of metastasis of an epithelial tumor in the renal graft and the first case described of renal cell carcinoma metastasis (R.C.C.) in the renal graft. This paper describes the case of a patient with a normally functioning renal transplant and A.C.R.D. who develops RCC in his own kidney, with metastasis in the renal graft.

KEY WORDS: Acquired renal cystic disease. Renal transplant. Renal adenocarcinoma.

$\mathrm{L}^{\mathrm{a}}$ a enfermedad renal quística adquirida E.R.Q.A), es un factor de riesgo para el desarrollo de carcinoma renal en los riñones propios, tras el trasplante renal (T.R.). El desarrollo de un tumor primitivo del injerto renal es infrecuente.

La presencia de metástasis en injerto renal de un tumor epitelial es excepcional, siendo este el segundo caso de literatura de metástasis de tumor epitelial en injerto y el primer caso descrito de metástasis de carcinoma de células renales (C.C.R.), sobre injerto renal. Presentamos el caso de un paciente con TR normofuncionante y ERQA que desarrolla CCR en riñón propio, con metástasis sobre el injerto renal. 


\section{CASO CLÍNICO}

Varón de 62 años en hemodiálisis por insuficiencia renal crónica (I.R.C.) secundaria nefropatía glomerular IgA. El paciente desarrolló ERQA a los dos años de iniciar la hemodiálisis. En 1989 se realiza TR con implante heterotópico en fosa iliaca derecha, con tratamiento inmunosupresor posterior con ciclosporina A y prednisona. A los seis años del trasplante el paciente acude al servicio de urgencias por presentar dolor lumbar derecho, sin sindrome miccional ni hematuria. La analítica demostró ligera anemia $10 \mathrm{gr} / \mathrm{dl}$, y función renal conservado (creatinina $1,8 \mathrm{mg} / \mathrm{dl}$ ) sin otros hallazgos de interés. Ecográficamente se objetivó un riñón derecho nativo con múltiples quistes, y una masa renal sólida de 70 milímetros de diámetro máximo. La tomografía axial (TAC) confirmó la existencia de una masa renal derecha (Fig. 1), sólida y vascularizada así como múltiples lesiones compatibles con enfermedad metastásica (adenopatías retroperitoneales, implantes subcutáneos, metástasis hepáticas). En el parénquima del injerto renal, aparecían múltiples lesiones sólidas y nodulares (Fig. 2). La punción aspiración por aguja fina (PAAF) realizada en la masa renal y en las lesiones nodulares del injerto renal confirmó la presencia en todas las muestras de CCR. Se inició tratamiento conservador con analgesia y reducción de las dosis de inmunosupresión, falleciendo el paciente a las tres semanas del diagnóstico de la enfermedad.

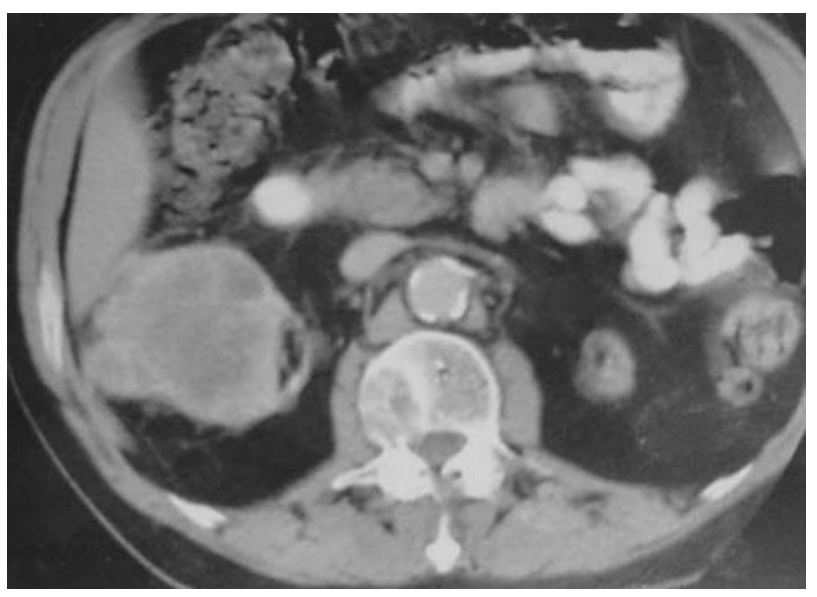

FIGURA 1

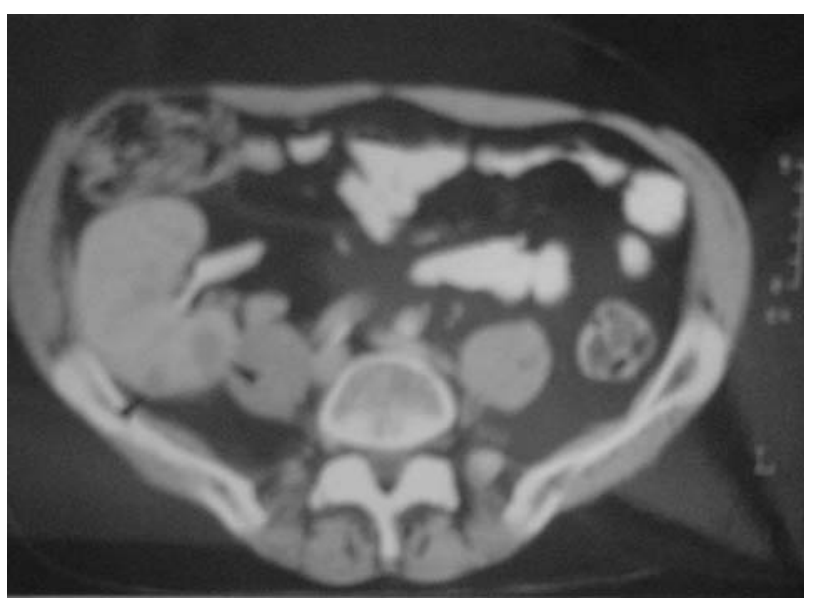

FIGURA 2

\section{DISCUSIŌN}

El TR es el tratamiento de elección en la IRC terminal. Sin embargo, la inmunosupresión crónica que conlleva el TR, incrementa el riesgo de infecciones y neoplasias, pudiendo llegar a ser el riesgo de estas según las series hasta 100 veces superiores que en la población normal ${ }^{4,5}$.

La incidencia de tumor en la población trasplantada, varia en la literatura entre el 1,6\% y el $18 \%$, con un valor medio del $6 \%^{1,4,5,12,19,20}$, siendo los tumores cutáneos los más frecuentes (carcinoma epidermoide y carcinoma basocelular), seguida por los linfomas y el sarcoma de Kaposi $^{4,9,10,12,19}$. Sin embargo, existe tras el TR un aumento de la incidencia de los tumores habituales en la población general (pulmón, mama, próstata y cervix) ${ }^{19,20}$. El tiempo de aparición de neoplasias tras el TR es diferente según el tipo; así el sarcoma de Kaposi es el más precoz en aparecer, seguido de los linfomas siendo el más tardío el tumor vulvar ${ }^{4,6,10,16,19}$.

La inmunosupresión, no solo produce un aumento de las neoplasias en pacientes trasplantada, sino que amplia la variedad de tipos histológicos, la manera de presentación y el comportamiento. Así existe una mayor incidencia de tumor cutáneo, vulva o cervix en pacientes tratados con azatioprina y corticoides, respecto al tratamiento con ciclosporina donde la presencia de linfomas es superior ${ }^{5,6}$.También se ha evidenciado una aparición más precoz de tumores en el TR cuando existe doble terapia inmunosupresora ${ }^{6,16}$. La terapia inmunosupresora potencia la agresividad 
de las neoplasias en el paciente con TR, confiriendo un peor pronóstico ${ }^{7}$. El origen de neoplasias en el paciente trasplantado, se puede deber $\mathrm{a}^{10}$ : cáncer trasplantado con el injerto, cáncer pre-existentes en el receptor, cáncer desarrollado de novo. El mecanismo oncogénico en el TR es multifactorial, destacando: periodo de uremia previo al TR, infecciones, terapia inmunosupresora, inhibición de la respuesta celular, agentes ambientales, y la presencia de ERQA ${ }^{4,16-21}$. El carcinoma de células renales, representa entre el $4,6 \%$ y el $7,6 \%$ de los tumores en el trasplantado renal $^{1,4,5,7,10,12,16,20}$; siendo la incidencia en nuestro medio de $5,9 \%{ }^{9}$, correspondiendo en mas del $70 \%$ de los casos a carcinoma de células renales ${ }^{11,12}$. El tumor renal en el paciente trasplantado aparece en edades más jóvenes que en la población general con una edad media de aparición entre 44 y 47 años; siendo la proporción hombre mujer de $2 a^{17,10}$. La ERQA fue descrita por primera vez en 1977 por Dunnill et al., definiéndose como la sustitución de mas del $25 \%$ del parénquima renal en pacientes con IRC por quistes córtico-medulares que se desarrollarían durante la diálisis, aunque se han descrito en pacientes con IRC prediálisis ${ }^{15,18}$. Etiopatogénicamente se han propuesto distintos mecanismos en la ERQA: obstrucción por depósitos de oxalato o fibrosis, productos tóxicos acumulados que alterarian la membrana basal, alteraciones vasculares secundarias a la hemodiálisis, factores renotrópicos de crecimiento ${ }^{17}$. La EQRA presentan quistes que afectan tanto a la médula como a la corteza, pudiendo medir desde varios milimetros a centímetros, siendo múltiples y bilaterales. Histológicamente se caracteriza por la presencia de quistes, cubiertos de epitelio cuboidal, columnar, o hiperplásico con proyecciones papilares. estudios patológicos han demostrada la continuidad de estos quistes con los túbulos renales, sugiriéndose el origen quístico en los túbulos, sin poder determinar si el origen es del túbulo proximal o distal ${ }^{8,9,15}$. Así los quistes tapizados por epitelio cuboidal se estratificaría, con posterior hiperplasia y displasia que daría lugar al tumor $^{18}$. Diversos autores destacan que a partir de los dos años en diálisis, los pacientes desarrollan en un $40 \%$ de los casos quistes renales bilaterales de tamaño diverso pero que no superiores a los 4 centímetros, aumentando la prevalencia de los quistes al 90\% en los pacientes en diálisis de más de 8 años de evolución ${ }^{7}$. La literatura se coincide mayoritariamente que el periodo entre el inicio de la hemodiálisis y la aparición de EQRA y el CCR son consecuencias de la IRC terminal y no secundarias al tiempo en hemodiálisis. Estudios realizados en pacientes con uremia tanto en programa de diálisis como sin él, presentan quistes renales que aumentan a medida que lo hace la creatinina sérica; de esta manera la relación que tendría la diálisis con la EQRA no sería de causa efecto sino que se debería al aumento de la expectativa de vida de los pacientes en diálisis ${ }^{15,18}$. La ERQA debe ser considerado como un potencial estadio premaligno con posibilidad de progresión a tumor en un $20 \%$, siendo la incidencia de tumores renales del 14 al $20 \%$, pudiendo desarrollar carcinoma de células renales entre 30 a 40 superior a la población general $^{2,7,8,15-18}$. La agresividad del tumor renal en pacientes con ERQA es baja, ya que suelen ser neoformaciones de pequeño tamaño, bien diferenciadas y de curso asintomático, siendo poco frecuente el desarrollo de metástasis (inferior al $1 \%)^{21,22}$.

El seguimiento de los pacientes con EQRA, dado su potencial premaligno deben ser vigilados a partir de los tres años en diálisis, anualmente mediante ecografia o TAC, siendo éste más sensible para detectar neoplasias pequeñas o la presencia de adenopatías retroperitoneales. El desarrollo de un tumor, en el contexto de la ERQA, en nuestra opinión exige nefrectomía . Sin embargo existe controversia, existiendo grupos que ante la presencia de tumoración inferior a 3 centímetros se aconsejan vigilancia semestral con TAC; realizando nefrectomía en el momento que se aprecie crecimiento tumoral o que la masa en el momento del diagnóstico sea superior a 3 centímetros ${ }^{17,18}$.

El origen de un tumor en el injerto puede ser: $1^{\circ}$ tumor de novo; $2^{\circ}$ trasferencia desde el donante; $3^{\circ}$ secundario o metastásico (siendo éste lo más usual). Han sido descritos en el injerto, tumores benignos como el adenoma tubulopapi$\operatorname{lar}^{13}$, y malignos como carcinoma de células renales ${ }^{1,4,5,9,14}$, linfomas no Hodgkin que según las series alcanzan hasta el $23 \%{ }^{10}$, y transferencias inadvertida de carcinoma renal ${ }^{7}$. El diagnóstico 
de estas lesiones debe llevarse mediante PAAF bajo control radiológico, obteniendo muestras de todas las áreas sospechosas. Se han descrito afectación secundaria del injerto por tumores linfoides, describiéndose hasta el momento solo un caso de metástasis de tumor sólido en el injerto renal, siendo el origen un carcinoma vesical ${ }^{3}$.

\section{CONCLUSIONES}

La aparición de metástasis de en el injerto renal es excepcional, siendo lo más usual la afectación del injerto por linfomas, habiéndose descrito hasta el momento un único caso de metástasis de tumor de origen epitelial en el injerto (carcinoma urotelial vesical).

Aportamos el segundo caso en la literatura de metástasis de carcinoma de origen epitelial; y el primer caso descrito de metástasis de carcinoma de células renales sobre injerto renal.

La posibilidad de metástasis sobre el injerto renal hace que esta entidad entre dentro del diagnóstico diferencial de lesiones sólidas del injerto renal.

\section{REFERENCIAS}

1. PENN I.: Primary kidney tumors before and after renal transplantation. Transplantation 1995; 59: 480-485.

2. ISHIKAWA I, ISHII H, SHINODA A.: Renal cell carcinoma of the native kidney after renal transplantation. A case report and review of the literature. Nephron 1991; 58: 354-358.

3. NURMI M, AHO H.: Metastasis from bladder carcinoma to renal transplant. Eur Urol 1989; 16: 310311.

4. PENN I.: Cancer in cadaver kidney transplant patients. Surgery 1984; 95: 377-378.

5. MARTÍNEZ JABALOYAS JM, RUIZ CERDÁ JL, OSCA JM.: Neoplasias en pacientes con trasplante renal. Actas Urol Esp 1994; 18: 562-568.

6. PENN I.: Cancers following cyclosporine therapy. Transplantation 1987; 43: 32-35.

7. PENN I: Occurrence of cancers in immunosuppressed organ transplant recipients. Clin Transpl 1994: 99-109.

8. LEVINE LA, GBUREK BM.: Acquired cystic disease and renal adenocarcinoma following renal transplantation. J Urol 1994; 151: 129-132.

9. HERMIDA GUTIÉRREZ JF.: Neoplasias en pacientes con trasplante renal. Tesis Doctoral 1998. Universidad Complutense Madrid.
10. PENN I.: The problem of cancer in organ transplant recipients: an overview. Transplant Sci 1994; 4: 2332.

11. COFAN F, PARRA E, SOLE M, RICART MJ.: Renal oncocytoma in a long-term renal-transplant recipient. Nephrol Dial Transplant 1996; 11: 395-396.

12. PENN I.: Incidence and treatment of neoplasia after transplantation. Heart Lung Transplant 1993; 12: 328-336.

13. JAO ST, WALTZER WC.: Appearance of a de novo renal tubulopapillary adenoma in an allograft recipient. Transplant Proc 1993; 25: 2133-2135.

14. HEINZ-PEER G, HELBICH T, NOTTLING B.: Renal cell carcinoma in an allograft kidney transplant. Transplantation 1994; 57: 475-478.

15. MICKISCH D, BOMMER J, BACHMANN S.: Multicystic trasformation of kidney sin chronic renal failure. Nephron 1984; 38: 93-99.

16. HERMIDA GUTIÉRREZ JF, MORENO SIERRA J, BLÁZQUEZ IZQUIERDO J.: Incidencia de neoplasias en pacientes con trasplante renal. ¿Está cambiando el patrón de neoplasias en estos pacientes? Arch Esp de Urol 1998; 51: 683-691.

17. JIMÉNEZ VERDEJO J.: Carcinoma renal y enfermedad quística adquirida del riñón en paciente trasplantado y en hemodiálisis. Act Urol Esp 1990; 14: 205-207.

18. CABALLERO JM, RIERA R, DOMINGO MA.: Asociación entre enfermedad quística renal adquirida y carcinoma renal: presentación de tres casos. Actas Urol Esp 1992; 16: 573-575.

19. HERMIDA GUTIÉRREZ JF, MORENO SIERRA J, BLÁZQUEZ IZQUIERDO J.: Neoplasias urológicas en pacientes con trasplanterenal. Experiencia y revisión de la literatura. Actas Urol Esp 1998; 22: 818-817.

20. GÓMEZ DOS SANTOS V, BURGOS REVILLA FJ, PASCUAL SANTOS J.: Prevalencias de neoplasias en el trasplante renal. Arch Esp Urol 1997; 50: 267 274.

21. JOVANOVIC D, KOVACEVIC Z, IVECK L.: Acquired renal cystc disease and renal carcinoma in patients on chronic hemodialisis. Vojnosanit Pregl 1998; 55: 333-337.

22. HERRERA PUERTO J, CARAVACA F, CASTAÑO CASASECA JL.: Hipernefroma en riñón nativo de paciente con trasplante renal. Actas Urol Esp 2003; 27 (5): 391-393.

Dr. I. Gómez García

C/ Maria Tubau, 15 - portal 3

Piso $1^{\circ} 3$

28050 Madrid

(Trabajo recibido el 2 febrero de 2004) 